NBER WORKING PAPER SERIES

\title{
THE IMPACT OF CLIMATE CHANGE SKEPTICISM ON ADAPTATION IN A MARKET ECONOMY
}

\author{
Matthew E. Kahn \\ Daxuan Zhao \\ Working Paper 23155 \\ http://www.nber.org/papers/w23155 \\ NATIONAL BUREAU OF ECONOMIC RESEARCH \\ 1050 Massachusetts Avenue \\ Cambridge, MA 02138 \\ February 2017
}

We thank Daron Acemoglu, Devin Bunten, Ed Glaeser and Josh Graff-Zivin for useful comments and suggestions. All remaining errors are ours. The views expressed herein are those of the authors and do not necessarily reflect the views of the National Bureau of Economic Research.

NBER working papers are circulated for discussion and comment purposes. They have not been peer-reviewed or been subject to the review by the NBER Board of Directors that accompanies official NBER publications.

(C) 2017 by Matthew E. Kahn and Daxuan Zhao. All rights reserved. Short sections of text, not to exceed two paragraphs, may be quoted without explicit permission provided that full credit, including $(\odot$ notice, is given to the source. 
The Impact of Climate Change Skepticism on Adaptation in a Market Economy

Matthew E. Kahn and Daxuan Zhao

NBER Working Paper No. 23155

February 2017

JEL No. Q54,R21

\begin{abstract}
Climate change will increase the risk of temperature extremes. Induced innovation could offset some of this threat. This paper explores the demand and supply for climate adaptation innovation in a market economy. Climate change induces this innovation because the rising temperatures increase demand for self protection products and for profit firms respond to these incentives. We then augment the model to introduce climate skeptics. Such skeptics reject the claim that the world is warming and thus do not increasingly demand adaptation products. We study how the economy's rate of adaptation innovation, cross city migration, real estate pricing and the welfare of agents with rational expectations are all affected by the presence of such skeptics.
\end{abstract}

Matthew E. Kahn

Department of Economics

University of Southern California

KAP

Los Angeles, CA 90089

and NBER

kahnme@usc.edu

Daxuan Zhao

Department of Finance

School of Business

Renmin University of China

Beijing

P.R. China, 100872

zhaodaxuan@gmail.com 


\section{Introduction}

Rising greenhouse gas emissions exacerbate the risk of severe climate change. Climate change poses a variety of ambiguous new challenges for agricultural production (Roberts, Schlenker and Eyer 2012, Burke and Emerick 2016), for cities close to coasts and rivers (Albouy et. al. 2016, Desmet, Nagy and Rossi-Hansberg 2015), for economic growth (Dell, Jones and Olken 2012; Deryugina and Hsiang 2014; Burke, Hsiang and Miguel 2015, Hsiang and Jina 2014) and for public health (DesChenes and Greenstone 2011).

Despite the scientific consensus concerning the risks posed by climate change, a large segment of U.S voters, members of Congress and the new Trump Administration view climate change as a low policy priority. ${ }^{1}$ In 2009, 212 U.S members of Congress voted against introducing a national carbon cap and trade market. Cragg et. al. (2013) document that Congressmen from poor, conservative areas whose local per-capita carbon footprint was high were much more likely to vote against the bill. Throughout this paper, we will refer to the set of people who do not view climate change to be a major quality of life challenge as "climate skeptics".

In this paper, we model how people adapt to a given level of aggregate greenhouse gas emissions when a proportion of the population are climate skeptics. We study how the well being of people with rational expectations is affected by the presence of climate skeptics and vice-versa. In our model, there is no collective action because there is no government. A group of individuals form an economy. As these individuals pursue their own self interest they exacerbate an environmental externality as a byproduct of private consumption. Each agent is small and takes the climate change challenge as a given but then chooses how to self protect against this emerging risk. We study endogenous adaptation innovation.

To set up the baseline, our first economy features a set of identical individuals who suffer from exposure to hotter temperature. As climate change raises temperature levels, each individual is willing to pay more to be exposed to less heat. In aggregate, this creates demand for products that facilitate adapting to the new climate conditions. Throughout this paper, we refer to this set of products as the "air conditioner". If aggregate demand for this product is sufficient, then for profit firms will design and sell the product (Acemoglu and Linn 2004).

Our model of climate change adaptation integrates several different literatures. Ehrlich and Becker (1972) model self protection against risks. In their model, people can invest in activities such as living in a safe neighborhood that reduce their exposure to risk. In our context, if an individual is exposed to less heat this reduces his death risk. We build on the Ehrlich and Becker (1972) work by studying how the aggregate demand for self protection affects innovation. Our problem mirrors Acemoglu and Linn (2004). They document that the aging of the large Baby Boomer cohort creates an increase in aggregate demand for new drugs that help this aging cohort. They find that drug companies direct research efforts to supply new drugs for which there is increasing demand. In our climate change adaptation setting, higher temperature increases the risk for all and this stimulates

\footnotetext{
${ }^{1}$ See http://www.pewresearch.org/fact-tank/2014/09/23/most-americans-believe-in-climate-change-but-give-itlow-priority/
} 
aggregate demand for pro-adaptation products.

As individuals engage in private self protection, they contribute to global greenhouse gas emissions (Davis and Gertler 2015). No individual air conditioner user has an incentive to internalize this externality. Air conditioner use both provides a private good (adaptation services to the individual) and a public bad (greater greenhouse gas emissions). We use our micro-founded model to characterize when this society's welfare is reduced by the induced innovation. This piece of the analysis differs from the case of induced new drug innovation which features no negative externalities associated with innovation.

We then relax the assumption that all consumers are identical and introduce the "climate skeptics". We assume that this group is unaware that temperature is an increasing function of greenhouse gas emissions. We study whether there is sufficient aggregate demand so that the air conditioner is introduced. The climate skeptics do not demand this product (and this lowers aggregate demand for it) and they increase the total severity of climate change by producing greenhouse gas emissions. We study how the well being of non-skeptics is affected.

In an extension of our basic model, we introduce two spatial locations that differ with respect to their baseline temperature. The cooler city is the safer city. Standard compensating differentials logic predicts that land rents will be higher there (Rosen 2002). Migration to the cooler city represents a substitute for air conditioning. This model allows us to highlight the interplay between locational choice and innovation. If people can move to a relative safe cooler place then this lowers their demand for products that offset climate risk and reduces the profit motive for innovators to offer such products. Since migration to a cooler place does not increase the stock of greenhouse gas emissions, the social planner prefers to use migration rather than introducing the air conditioner to protect the population. Limited housing supply in the safer areas bounds the use of this protection strategy. We explore how the existence of climate skeptics (who do not increasingly demand to live in the cooler safer city) benefits the rational agents because this group pays lower rents for temperate areas relative to what they would have paid if all agents are rational.

The remainder of this paper is organized as follows: Section 2 presents the baseline model where adaptive innovation is intended to reduce climate change risk; section 3 extends the model to multiple cities. In Section 4, we study the interplay between locational choice and innovation in the presence of climate skeptics. Section 5 concludes.

\section{Induced Innovation Intended to Reduce Climate Change Risk}

In this section, we present a model featuring a large number of individuals who suffer from the rising temperature caused by climate change. If an air conditioner exists, each individual can offset the negative effects of heat through air conditioning but in aggregate this creates a feedback effect as aggregate rising electricity demand increases greenhouse gas emissions which exacerbates climate change risk (Davis and Gertler 2015, Nordhaus 2011). Using our model, we discuss the individual's optimal consumption, the probability that innovation takes place and how this equilibrium compares 
to the Pareto optimum.

\section{$2.1 \quad$ Preferences}

Consider a static model in which each person in the economy seeks to maximize his expected utility. There are $N$ identical people. Each person's expected utility is represented by;

$$
s(q) u(c)
$$

where $c$ is the consumption each person and $s(q)$ is the probability that each person survives to enjoy consumption. This survival probability is a function of $q$ which denotes the risk that each individual faces. To simplify our discussion, we focus on temperature as the single risk. Here $q$ is the temperature $T$ that affects a person's survival probability. We assume that

$$
s^{\prime}<0 \text { and } s^{\prime \prime}<0,
$$

since the survival rate is decreasing with respect to temperature ${ }^{2} . u(c)$ is a twice differentiable utility function. We assume that

$$
u^{\prime}>0 \text { and } u^{\prime \prime}<0 \text {. }
$$

A person's utility is increasing with respect to consumption.

Each person has an exogenously determined income of $y$. Each person's budget constraint can be expressed as;

$$
c \leq y
$$

Throughout this paper, we assume that climate change has no impact on individual or aggregate income. This is a simplifying assumption but we recognize that we are ruling out certain climate change scenarios. In particular, a set of macro studies such as Weitzman (2009) and Costello et. al. (2010) have modeled how climate change can increase the likelihood of rare disasters (which is modelled as a huge drop in consumption). Nordaus and Boyer (2003) model the feedback effect for how climate change impacts aggregate income. Deryugina and Hsiang (2015) use cross-county U.S data to estimate the recent historical impact of temperature on per-capita income. Under a business as usual scenario, they predict that warmer daily temperatures will lower annual growth by roughly .1 percentage points.

By not allowing for a direct income effect caused by climate change, we are assuming that the world population is urbanized and faces medium term smooth (rather than abrupt) climate change. Economies such as Singapore have demonstrated a continued capacity to grow despite constant exposure to high heat and humidity. Future research could model how endogenous innovation is affected by declining incomes caused by climate change. We posit that there are two offsetting

\footnotetext{
${ }^{2}$ We do not consider the polar case in which the initial temperatures are extremely low and warming raises survival rates.
} 
effects. First, lower income means that people face limits on their ability to pay for adaptation goods and this reduces aggregate demand for such self protection goods. On the other hand, if climate change's path is predictable then in a dynamic model, forward looking patient agents may be willing to invest earlier in such adaptation goods to guarantee that their incomes are not reduced by future heat. There is also the possibility that firms will invest in adaptation technology to shield their workers from expected heat (Graff-Zivin and Kahn 2016). Such firm level demand for adaptation products creates an additional source of revenue for adaptation suppliers. Our model abstracts from dynamic considerations and people receive an income endowment rather than working for a firm.

\subsection{The Demand for Air Conditioning}

Each person in our economy takes the temperature as an exogenous variable. Since temperature increases lead to a lower survival rate, each person is willing to pay more for products to offset this heat exposure. The air conditioner is the only possibly available self protection product.

If a person does not purchase an air conditioner, then the temperature he faces (the indoor temperature) is equal to the outdoor temperature $T$. A person who owns an air conditioner can adjust the indoor temperature $q$ by operating it but this requires sacrificing some consumption to purchase the required electricity to run the air conditioner. The person's survival rate increases by owning and operating the air conditioner as the survival rate increases from $s(T)$ to $s(q)$. For a person who owns an air conditioner, this person's budget constraint can be written as:

$$
c+\eta \tau(T-q)+P \leq y,
$$

where $P$ is the price of air conditioner; $\eta$ is price of electricity ; and $\tau$ describe the efficiency of air conditioners i.e. the electricity consumption required for reducing temperature by one degree ${ }^{3}$.

If the outdoor temperature is $T$, the person will buy the air conditioner only when

$$
s(q) u[y-\eta \tau(T-q)-P] \geqslant s(T) u(y) .
$$

This condition states that the person buys the air conditioner when the utility from owning it is greater than the utility from not buying it. This equation can be used to solve for the maximum willingness to pay for the air conditioner which is the value $P$ that solves. If the maximum willingness to pay for the air conditioner is $\bar{P}$, we write;

$$
s(q) u[y-\eta \tau(T-q)-\bar{P}]=s(T) u(y)
$$

The comparative statics are straightforward.

Proposition 1. $\frac{\partial \bar{P}}{\partial T}>0$ and $\frac{\partial \bar{P}}{\partial y}>0$. The willingness to pay for an air conditioner is an increasing function of the outdoor temperature $T$ and income $y$.

\footnotetext{
${ }^{3}$ Our model is a one-period model. The time duration is long enough such that the air conditioner fully depreciates by the end of this period.
} 


\subsection{Adaptation Technology Supply}

Air conditioner production requires that a producer incurs a fixed cost of $F$ and a variable cost of $V$. Any producer can enter the market costlessly. Therefore, a producer will set the price at the average cost and earn zero profit. Each of the $N$ people are willing to pay $P$ for an air conditioner. The for profit firm will enter the market if this revenue $N \times P$ is greater than or equal to the total cost $F+N \times V$. Therefore, the price of the air conditioner will be determined by;

$$
P=\frac{F}{N}+V
$$

The price of the air conditioner decreases with the scale of the market and increases with the cost of production.

In a more realistic model of $\mathrm{R} \& \mathrm{D}$, some of these innovation efforts could fail but as long as the expected profits are positive, then there is sufficient incentive for innovators to enter the market.

\subsection{Climate Change}

We introduce climate change as a forcing process that increases average temperatures as the cumulative stock of greenhouse gas emissions (GHG) increases. This approach follows Nordhaus (2011) who models how world temperature affects per-capita income and then models the feedback from global income to the temperature level.

We assume that temperature is a sufficient statistic for the climate at the location where people live. We label the outdoor temperature as $T$. We assume that the temperature rises in proportion to total aggregate consumption such that

$$
T=\phi N c+T_{0}
$$

where the parameter $\phi$ measures the strength of climate change due to consumption, and $T_{0}$ is the minimum temperature in the absence of economic activity. ${ }^{4}$

Electricity is an input in running one's air conditioner. Electricity and composite consumption are allowed to have different greenhouse gas emissions factors. We assume that the outdoor temperature is related to total consumption based on the equation;

$$
T=\phi N c+\varphi N \tau(T-q)+T_{0},
$$

where the parameter $\phi$ measures the strength of climate change due to consumption; $\varphi$ is the strength of climate change led by electricity consumption; and $\tau$ is the efficiency parameter representing electricity consumption for one degree temperature reduction. This equation introduces the feedback of how aggregate consumption affects the environment.

\footnotetext{
${ }^{4}$ Recall that in our static economy that people live for one period. If previous generations consumed goods and created greenhouse gas emissions then $T_{0}$ for the current generation will be higher because of the consumption of the previous generation. In this sense, climate change entails an intergenerational externality.
} 


\subsection{Social Welfare and the Climate Change Adaptation Technology}

The social welfare function is defined as the sum of each individual's expected utility. If there is no adaptive innovation, then social welfare will increase with the growth of income and then decrease since that income growth causes two effects. First, income growth causes higher temperature which reduces the survival rate. Second, higher income raises each individual's consumption. In the appendix, we solve for the conditions such that the climate adaptive technology increases social welfare.

In our model, the fixed cost of production $F$ is related to the efficiency parameter $\tau$. The efficiency of the adaptive technology will continuously improve if there is sufficient market demand, such that: first, a larger population reduces the average $R \& D$ cost for designing more efficient air conditioners. Second, as individual income increases, people can afford the more efficient technology. Third, if the electricity price is high, then people are willing to purchase a more efficient air conditioners. ${ }^{5}$

\subsection{Effects of "Climate Skeptics" on Induced Innovation}

We now allow for a subset of the agents to be unaware of the fact that climate change is occurring. These "climate skeptics" simply believe that the temperature never changes. The population of "behavioral naive agents" in our economy is $N^{b}$ and the remainings are rational agents, $N^{b} . N^{r}+$ $N^{b}=N$. We define $\omega=N^{b} / N$ as the percentage of "climate skeptics" in our economy. Since the skeptics are unaware that the aggregate temperature is rising, their willingness to pay for the air conditioner is too low. Our model assumes that the skeptics do not update their survival probabilities as temperature increases. The utility function for the skeptic is ${ }^{6}$

$$
u^{b}=u(c)
$$

and the rational agents' expected utility is

$$
u^{r}=s(q) u(c)
$$

Climate change is driven by total emissions. In the absence of adaptation innovation, the temperature exposure for all agents follows the process presented in equation 7 .

The pricing function is defined in equation 6. However, the demand for the air conditioners is no longer equal to the number of total agents. Only rational agents purchase air conditioners. The pricing function is:

$$
P=\frac{F}{(1-\omega) N}+V
$$

Consider the condition determining induced innovation in equation 4 .

\footnotetext{
${ }^{5}$ In the Appendix, we present a detailed discussion establishing these claims.

${ }^{6}$ Climate skeptics take the survival rate as a constant value since they are unaware that it is decreasing as a function of climate change. To simplify our discussion, the initial survival rate is assumed to be 1.
} 
In our economy, the income $y$ is exogenous. As equation 7 shows, the average temperature increases with the income and the willingness to pay on air conditioners also increases with income. We define a $\bar{y}$ as the key cutoff such that the air conditioners will be produced when $y \geq \bar{y}$. It satisfies that

$$
s(q) u[\bar{y}-\eta \tau(T-q)-P]=s(T) u(\bar{y}) .
$$

Substitute equation 7 and 9 into equation 10; and differentiate it with respect to $\omega$, we have $\frac{\partial \bar{y}}{\partial \omega}>0$.

Proposition 2. The climate adaptive innovation will only occur if the income level for individuals is much higher in an economy featuring "climate skeptics". $\frac{\partial \bar{y}}{\partial \omega}>0$.

If the economy features a large share of climate skeptics, then there is not enough aggregate demand to encourage adaptation innovation.

\subsection{Applying the Lucas Critique to Climate Change Adaptation}

The original Lucas Critique focused on how the optimal decision rules of consumers change as government changes "the rules of the game" (Lucas 1976). If consumers change their consumption patterns when a permanent tax cut is enacted, then historical estimates of the marginal propensity to consume out of current income will not be useful in predicting future behavior under the new policy.

Here we seek to apply this same logic in the case of climate change. While there is no government in our model, Mother Nature has changed the "rules of the game". As temperatures increase, a researcher who seeks to extrapolate what the death rate will be based on the pre-air conditioner time series of data on death rates and temperature would overstate the relationship.

An econometrician who calculates the death rate at a point in time before the air conditioner is induced and plots this with respect to temperature would over-estimate the long run increase in the death rate caused by climate change. This econometrician's reduced form model implicitly assumes that the rising temperature will not trigger an adaptation response. In the "no adaptation" case, historical relationships between the death rate and temperature can be used to predict future impacts caused by climate change. As shown by our model, the induced innovation takes place because of climate change. Rising temperatures increase the willingness to pay for innovation and the aggregate market potential induces product entry.

In an economy where the adaption technology is introduced, researchers will observe the temperature $T$ and the survival rate $s(q)$ where $q$ is solved from the person's optimal consumption problem ${ }^{7}$.

Figure 1 illustrates this relationship. When the temperature is lower than $T^{*}$ which is the critical value of adaptive innovation, the probability of death increases with temperature. At the critical value $T^{*}$, there is a structural break since the induced innovation decreases the death rate. This finding highlights that the Social Cost of Carbon, defined as the aggregate willingness to pay for

\footnotetext{
${ }^{7}$ The detailed solution is in the web appendix. Please refer to equation 15 and 16.
} 


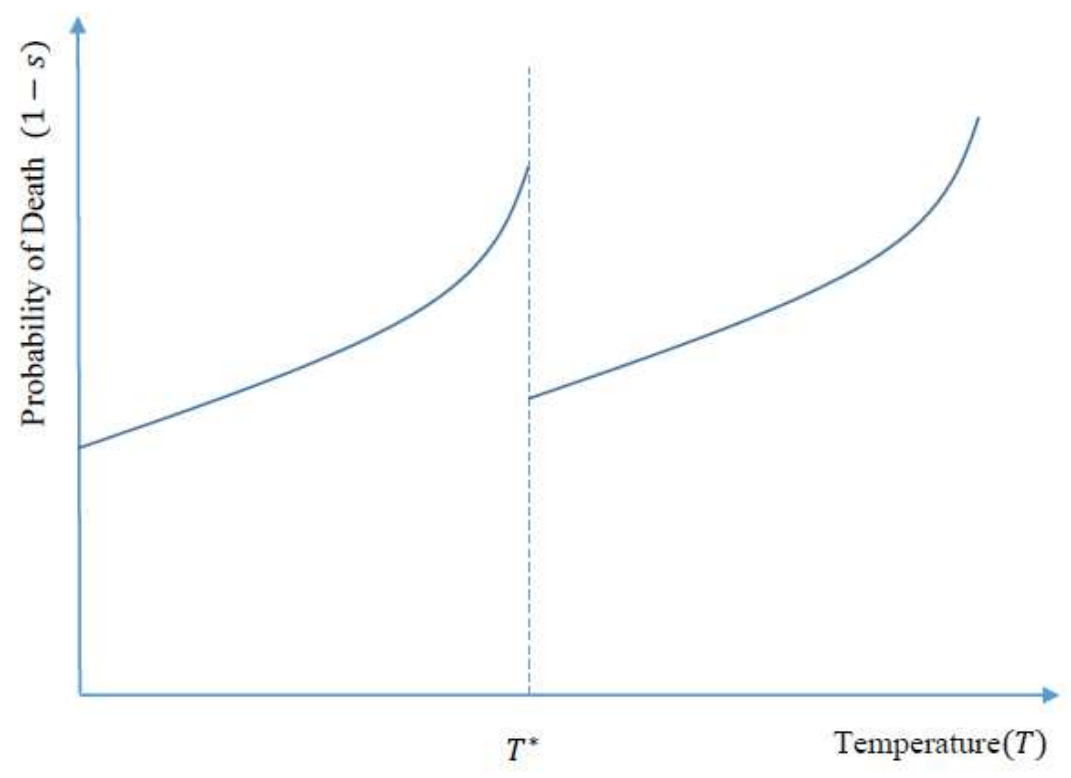

Figure 1: The Probability of Death as a Function of Temperature

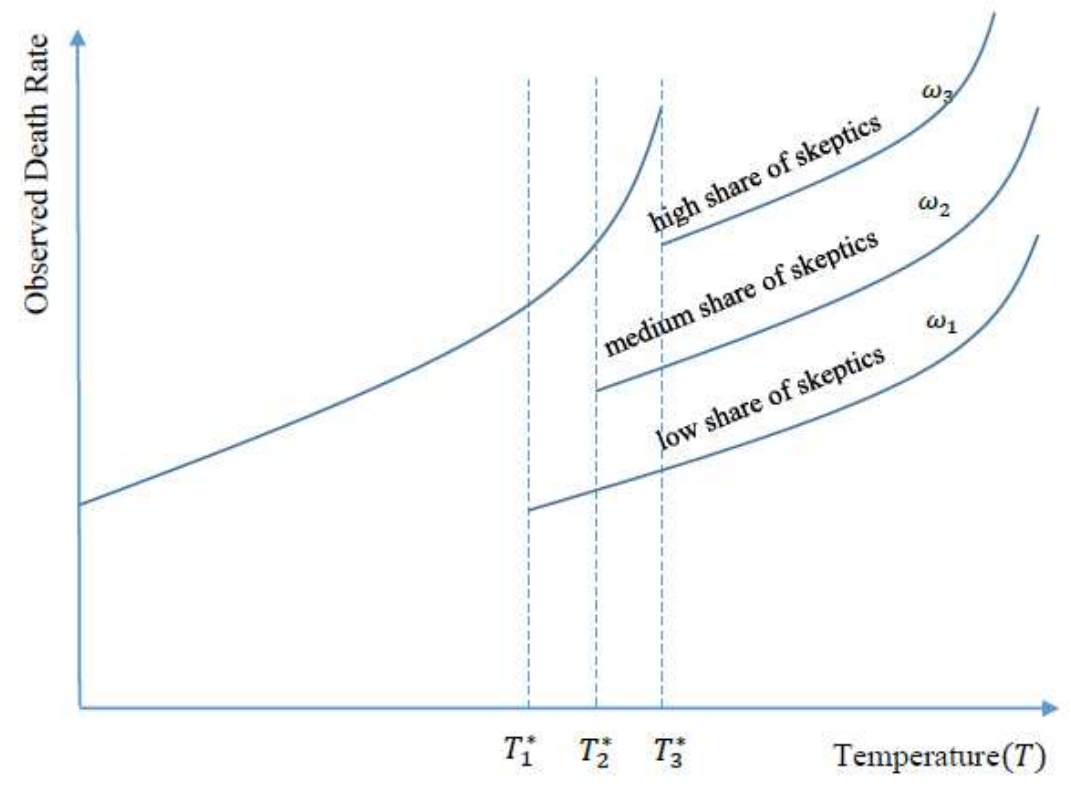

Figure 2: The Observed Death Rate in the Presence of "Climate Skeptics" 
an extra ton of carbon dioxide to not be released, can decline over time if adaptation innovations involve a fixed production cost.

An economy featuring climate skeptics will exhibit a different time series path documenting the relationship between the death rate and outdoor temperature. As shown in Figure $2, T_{1}^{*}, T_{2}^{*}$ and $T_{3}^{*}$ are the critical temperatures such that the adaption technology is induced in economies 1, 2, and 3 respectively. The three economies differ with respect to their share of agents who are skeptics. We have $\omega_{1}<\omega_{2}<\omega_{3}$. The economy featuring a larger share of skeptics will induce adaptive technology later (when temperatures are higher). This claim is based on the fixed cost of introducing the new technology. For profit firms will only develop the product if aggregate demand is high enough. Holding population and income constant, this aggregate demand for the innovation is lower if the share of skeptics is higher.

"Climate skeptics" do not purchase air conditioners even when the adaptation technology is available. Their death rate keeps growing with the temperature and only rational agents experience a structural beak once the air conditioner is induced. The observed overall death rate is the weighted average of the death rates for the two types of agents.

\section{Adaptation Through Migration and Innovation}

In this section, we introduce an extension of the model by allowing people to choose between living in two cities. These locations differ with respect to their average temperature with one being cooler than the other. The cooler city thus offers a flow of "natural capital" such that one's demand for air conditioning is lower if one lives in that city. As we discuss below, each individual will pay a city specific rent. The cooler city will feature higher rents but its residents will have lower operating costs for running their air conditioners (if the air conditioner is invented). In equilibrium, individuals will be indifferent between living in the two cities but as we study below the social planner would prefer to pack more people into the cooler city because this reduces overall risk exposure to higher temperatures without exacerbating the climate change externality.

Migration and adaptation innovation are substitutes in reducing population risk exposure. Their respective welfare effects hinge on the specifics for a given economy.

\subsection{The Spatial Model}

Consider two cities in an economy. All economic agents have the same preferences and face zero migration costs. This guarantees that all will be attracted to the cooler city if rents are zero. We study how climate change and the introduction of an adaptive technology influence the spatial equilibrium.

The two cities are denoted as $i \in\{1,2\}$. We assume that the baseline temperature $T_{0 i}$ differs between two cities because of the heterogeneity of geographical factors, such as latitude, altitude, distance from the coast. Climate change raises temperatures in both cities. The temperature $T_{i}$ for city $i$ is related to the baseline temperature $T_{0 i}$ and the total emissions as shown in equation 7 . To 
simplify our discussion, we assume city $i=1$ is always hotter, i.e. $T_{1}>T_{2}$. We have

$$
T_{1}=T_{2}+\Delta T, \text { and } \Delta T>0
$$

where $\Delta T$ indicates the temperature gap between two cities.

We assume that the two cities are of equal size and that each contains half of the housing and that no more homes can be constructed. Each city can provide $N / 2$ units of houses. The rent is $R_{i}$ in city $i$. Each period each person chooses where to live and consumes his endowment of income. This income can be spent on consumption and housing if the air conditioner does not exist and it can be spent on consumption, electricity, housing and renting the air conditioner if the air conditioner is created. The budget constraint without air conditioners will be

$$
c+R_{i} \leq y
$$

People in city $i$ have a utility $u_{i}$ if they do not have air conditioners,

$$
u_{i}=s\left(T_{i}\right) u\left(y-R_{i}\right)
$$

We assume the rents are collected by one landlord and fully spent on the consumption of composite commodity.

If air conditioners are purchased, each person's budget constraint will be

$$
c+P+\kappa\left(T_{i}-q_{i}\right)+R_{i} \leq y,
$$

where $q_{i}$ is the indoor temperature with air conditioners. The utility function for people with air conditioners in city $i$ is

$$
u_{i}=s\left(q_{i}\right) u\left(y-P-\kappa\left(T_{i}-q_{i}\right)-R_{i}\right) .
$$

Definition. The interior equilibrium is given a temperature in each city $\left\{T_{1}, T_{2}\right\}$, a set of prices $\left\{P, R_{1}, R_{2}\right\}$, and aggregate air conditioners output $\{M\}$ such that:

1. People maximize their own utility.

2. The producers of air conditioners maximize profit if air conditioners are produced. Equation 6 holds.

3. The utility is equalized across the two cities.

$$
u_{i}=\bar{u},
$$

where $\bar{u}$ is constant. 
4. The housing markets clear in each city.

$$
N_{i}=N / 2
$$

5. If air conditioners are produced, the air conditioner market clears

$$
\int I=M
$$

and each person buys an air conditioner.

\subsection{The Spatial Equilibrium}

In equilibrium, each person's utility will be equalized across the two cities. From equation 11, the equilibrium condition is

$$
s\left(T_{i}\right) u\left(y-R_{i}\right)=\bar{u} .
$$

Based on equation 12 , the spatial equilibrium condition for agents will be,

$$
s(q) u\left(y-P-\kappa\left(T_{i}-q_{i}\right)-R_{i}\right)=\bar{u} .
$$

Specifically, the optimal indoor temperature can be found based on the first-order condition of the utility function;

$$
s^{\prime}\left(q_{i}\right) u\left(y-P-\kappa\left(T_{i}-q_{i}\right)-R_{i}\right)+\kappa s\left(q_{i}\right) u_{1}\left(y-P-\kappa\left(T_{i}-q_{i}\right)-R_{i}\right)=0 .
$$

Proposition 3. The rent decreases with the local temperature. The local rent compensates people for temperature risk. $\frac{d R_{i}}{d T_{i}}<0$.

High local temperature reduce survival rates. Rational agents are aware of this risk. They are willing to pay higher rents to live in the safer city. This willingness to pay is related to the income level. If air conditioners are bought by agents, air conditioners can offset climate risk. But, air conditioner usage is costly. Recognizing this, people will want to live in the cold city since it reduces death risk. This implies that the hotter city features lower rents.

Proposition 4. Since there are only rational agents in this model and the agents do not have an air conditioner, the equilibrium rent will be more sensitive to income when the income increases. $d\left(\frac{d R_{i}}{d T_{i}}\right) / d y>0$. If there are only rational agents in the model and agents have an air conditioner, the rent will be less sensitive to income when the income increases. $d\left(\frac{d R_{i}}{d T_{i}}\right) / d y<0$.

When income is lower than the break-even income $y^{*}$, peoples do not buy air conditioners and the rent is related to the local temperature. However, as proposition 4 showed, the rent difference between the two cities increases with income. When the income of agents is higher than $y^{*}$, air conditioners are purchased. The rent difference between cities will decrease with the increasing income. 


\section{The Spatial Equilibrium and Innovation in an Economy Featuring Climate Skeptics}

We now model how the spatial equilibrium is affected by the existence of climate skeptics. The rational agents will tend to cluster in the cooler city. Whether they pay a rent premium for this amenity hinges on whether they or the skeptics are the marginal buyer of housing. If the share of skeptics in the economy is large, then the rational agents will live in the cooler city and not pay a rent premium. In such an economy, the air conditioner is less likely to be invented because the skeptics do not demand it and the rational agents offset the heat through where they live and thus are now willing to pay less for the air conditioner.

\subsection{The Spatial Equilibrium with Two Types of Agents}

We extend our two-city model. We define $N_{i}^{x}$ to denote the distribution of these two types of agents between two cities, $x \in\{r, b\}$. The total population in city $i$ is $N_{i}=N_{i}^{r}+N_{i}^{b}$.

We study the location choice and consumption patterns of both sets of agents. The new equilibrium is defined as follows:

Definition. The interior equilibrium is given by the temperature in each city $\left\{T_{1}, T_{2}\right\}$, a set of rents $\left\{P, R_{1}, R_{2}\right\}$, the allocation of people $\left\{N_{1}^{r}, N_{2}^{r}, N_{1}^{b}, N_{2}^{b}\right\}$, and aggregate air conditioners output $\{M\}$ such that:

1. People maximize their utility.

2. The producers of air conditioners maximize profit if air conditioners are produced. Equation 6 holds.

3. No individual perceives that he can raise his utility by moving to a different city.

$$
u_{1}^{b}=u_{2}^{b} \text { and } u_{1}^{r}=u_{2}^{r}
$$

4. The housing markets clear in each city.

$$
N_{i}^{r}+N_{i}^{b}=N_{i}=N / 2
$$

5. If air conditioners are produced, the air conditioner market clear.

$$
\int I=M
$$

where each person has an air conditioner.

If the number of rational people is less than half of total population, they will only concentrate in the cold city. The land rent in each city is decided by the marginal agent. If the number of 
rational agents is less that half of total population $N^{r}<N / 2$, the marginal agent is the behavioral agent. Since behavioral agents do not recognize the threat of climate change, the rent premium in the cooler city will not increase over time. If the number of rational agents is greater than half of the total population $N^{r} \geq N / 2$, the marginal agent is the rational agent. In this case, the land rent is decided by the spatial equilibrium condition $u_{1}^{r}=u_{2}^{r}$.

The rational agents thus benefit from lower rents in the cool city if their share of the population is low. If there are many "climate skeptics" in the economy, the cool city's rents will be low and will not reflect the increasing actual death risk from living in the hotter city.

\subsection{The Interplay Between Induced Innovation and Migration in an Economy Featuring "Climate skeptics"}

The key condition determining whether there will be production of air conditioners is shown in equation 6. The count of the rational agents plays a crucial role here. If the number of rational agents is less that half of the total population $N^{r}<N / 2$, they will all live in the cold city. Only when that city's temperature rises above the critical threshold, or if the rational agents' income increases enough, will they demand air conditioners. The price of air conditioners will be

$$
P=\frac{F}{N^{r}}+V
$$

Consider the break-even condition as shown in equation 4, the break-even temperature $T^{*}$ at city 2 (cold city ) will decrease with the number of rational agents. When $T_{2}>T^{*}$, rational agents in city 2 buy air conditioners.

If the number of rational agents is more than half of total population $N^{r} \geq N / 2$, rational agents will occupy the cold city first and then start to live in the hot city. If only the rational agents in the hot city purchase air conditioners, the price of air conditioners will be

$$
\hat{P}=\frac{F}{N^{r}-N / 2}+V
$$

The price of the air conditioner should satisfy the following equations

$$
\begin{aligned}
& s\left(q_{1}\right) u\left[y-\hat{P}-\kappa\left(T_{1}-q_{1}\right)-R_{1}\right] \geq s\left(T_{1}\right) u\left(y-R_{1}\right), \\
& s\left(q_{2}\right) u\left[y-\hat{P}-\kappa\left(T_{2}-q_{2}\right)-R_{2}\right]<s\left(T_{2}\right) u\left(y-R_{2}\right) .
\end{aligned}
$$

$T^{*}$ is the break-even temperature, and then $T_{1}>T^{*}>T_{2}$. This equation implies that only agents in the hot city purchase air conditioners. If the temperature is high enough, all rational agents will start to use air conditioners as the price of air conditioners decreases (due to the scale effect in production). In this case, $T_{2}$ is greater than $T^{*}$.

To summarize, if the count of non-skeptics is small, this group will cluster in the cool city and the air conditioner will not be induced until the overall temperature in the cool city is very high. 
If the count of skeptics is small, the rational agents will locate in both cities. The rent discount for the hot city will rise over time and rational agents in both cities will demand the air conditioner and it will be more quickly induced into being produced.

\section{Conclusion}

Climate change imposes a threat to our quality of life. Both innovation and migration could help us to adapt to this threat. Market technologies can be invented that can offset some of the climate change threat but at a cost. In our model of a market economy without an active government, the adaptation technology does not originally exist but it is invented because climate change increases the aggregate demand for it. When we introduce the spatial economy, rational agents seek to move to the place that is less affected by climate change. Supply side limits of land and fixed costs to innovation raise the adaptation price.

We then introduce climate skeptics as a set of consumers who do not perceive climate change to represent an increasing threat to their quality of life. We model how the innovation process by for profit firms and the spatial equilibrium is affected by the presence of people who are climate skeptics. The skeptics are willing to pay less for adaptation solutions because they do not perceive the severity of the climate risk.

Financial research has studied how the well being of rational agents is affected by the presence of behavioral agents (see Campbell 2016). Our paper has extended this approach to the economics of climate change adaptation. The presence of a larger share of climate skeptics impacts innovation, migration and real estate prices and thus the well being of the rational agents. Climate skeptics do not demand adaptive innovation and are not willing to pay a price premium to live in the cooler city. Holding total population constant, an increase in the number of climate skeptics reduces the aggregate demand for land in the cool city and reduces the demand for adaptation innovation. This lowers the market price of land in the cool city but raises the price of adaptation products because fewer people are willing to bear the R\&D cost.

Future research could relax our maintained assumption that the skeptics never update their beliefs and demand adaptation products. This dynamic should increase the rate of innovation. If skeptics are prone to update their information and change their minds about climate change, then

this highlights the role that the media and persuasion play in facilitating climate change adaptation through market product innovation. In this case, skeptics benefit from the presence of rational agents because the skeptics would now have an option to later purchase climate adaptation goods. These goods exist because of the earlier aggregate demand by non-skeptics. 


\section{References}

[1] Acemoglu, D., 2002. Directed Technical Change?, Review of Economic Studies, 69(4): 781-09.

[2] Acemoglu, D., and Linn, J., 2004. Market Size in Innovation: Theory and Evidence from the Pharmaceutical Industry, Quarterly Journal of Economics, 119(3): 1049-1090.

[3] Albouy, D., Graf, W. F., Kellogg, R., and Wolff, H., 2016. Climate Amenities, Climate Change, and American Quality of Life, Journal of the Association of Environmental and Resource Economists, 3(1): $205-246$.

[4] Andreoni, J., and Levinson, A., 2001. The Simple Analytics of the Environmental Kuznets Curve. Journal of Public Economics, 80(2):269-286.

[5] Barreca, A., Clay, K., Deschenes, O., Greenstone, M., and Shapiro, J.S., 2016. Adapting to Climate Change: The Remarkable Decline in the US Temperature-Mortality Relationship over the Twentieth Century, Journal of Political Economy, 124(1):213 - 250.

[6] Bunten, D., and Kahn, M. E., 2017. Optimal Real Estate Capital Durability and Localized Climate Change Disaster Risk, Journal of Housing Economics.

[7] Burke, M., Hsiang, S. M., and Miguel, E., 2015. Global Non-linear Effect of Temperature on Economic Production, Nature, 527: 235-239.

[8] Campbell, J. Y., 2016. Restoring Rational Choice: The Challenge of Consumer Financial Regulation, American Economic Review, 106(5):1-30.

[9] Costello, C. J., Neubert, M. G., Polasky, S. A., and Solow A.R., 2010, Bounded Uncertainty and Climate Change Economics, Proceedings of the National Academy of Sciences, 107(18):8108-10.

[10] Davis, L.W., 2008, Durable Goods and Residential Demand for Energy and Water: Evidence from a Field Trial, The RAND Journal of Economics, 39(2):530-46.

[11] Davis, L.W., and Gertler, P. J., 2015. Contribution of Air Conditioning Adoption to Future Energy Use under Global Warming, Proceedings of the National Academy of Sciences, $112(19): 5962-7$.

[12] Dell, M., Jones, B. F., and Olken, B. A., 2012. Temperature Shocks and Economic Growth: Evidence from the Last Half Century, American Economic Journal: Macroeconomics, 4(3): $66-95$.

[13] Deryugina, T., and Hsiang, S. M., 2014. Does the Environment Still Matter? Daily Temperature and Income in the United States, No. w20750. National Bureau of Economic Research.

[14] Deschênes, O., and Greenstone, M., 2007. The Economic Impacts of Climate Change: Evidence from Agricultural Output and Random Fluctuations in Weather, American Economic Review 97(1): 354-385. 
[15] Deschênes, O., and Greenstone, M., 2012. The Economic Impacts of Climate Change: Evidence from Agricultural Output and Random Fluctuations in Weather: Reply, American Economic Review 102(7): 3761-3773.

[16] Deschênes, O, and Greenstone, M., 2011. Climate Change, Mortality, and Adaptation: Evidence from Annual Fluctuations in Weather in the US, American Economic Journal: Applied Economics, 3(4): 152-85.

[17] Desmet, K, Nagy, D. K, and Rossi-Hansberg, E., 2015. The Geography of Development: Evaluating Migration Restrictions and Coastal Flooding. National Bureau of Economic Research.

[18] Ehrlich, I., and Becker, G. S., 1972. Market Insurance, Self-Insurance, and Self-Protection, Journal of Political Economy, 80(4): 623-648.

[19] Hsiang, S. M., and Jina, A. S., 2014. The Causal Effect of Environmental Catastrophe on Long-run Economic Growth: Evidence from 6,700 Cyclones, No. w20352. National Bureau of Economic Research.

[20] Lucas, R. E., 1976. Econometric Policy Evaluation: A Critique. In Brunner, K., and Meltzer, A. The Phillips Curve and Labor Markets. Carnegie-Rochester Conference Series on Public Policy. New York: American Elsevier: 19-46.

[21] Nordhaus, W. D., 2011. Estimates of the Social Cost of Carbon: Background and Results from the RICE-2011 Model, No. w17540. National Bureau of Economic Research.

[22] Nordhaus, W. D., 2015. Climate Clubs: Overcoming Free-riding in International Climate Policy. American Economic Review 105(4): 1339-1370.

[23] Nordhaus, W. D., and Boyer, J., 2003. Warming the World: Economic Models of Global Warming. MIT press.

[24] Nordhaus, W. D., and Yang, Z., 1996. A Regional Dynamic General-equilibrium Model of Alternative Climate-change Strategies, American Economic Review, 1:741-65.

[25] Pindyck, R. S., 2013. Climate Change Policy: What do the Models Tell Us?. Journal of Economic Literature, 51(3): 860-72.

[26] Roberts, M. J., Schlenker, W., and Eyer, J., 2012. Agronomic Weather Measures in Econometric Models of Crop Yield with Implications for Climate Change, American Journal of Agricultural Economics, aas047

[27] Stokey, N. L.,1998. Are there Limits to Growth?, International Economic Review, 39(1):1-31.

[28] Weitzman, M. L., 2009. On Modeling and Interpreting the Economics of Catastrophic Climate Change, Review of Economics and Statistics, 91(1): 1-19. 
[29] Zivin, J. G., and Kahn, M. E., 2016. Industrial Productivity in a Hotter World: The Aggregate Implications of Heterogeneous Firm Investment in Air Conditioning. No. w22962. National Bureau of Economic Research. 


\section{Web Appendix}

\section{A The Welfare Effects from Induced Adaptation Innovation}

We study how social welfare is affected by adaption innovation. The social welfare function is defined as the sum of each individual's expected utility. First, we discuss the planner's problem in the absence of air conditioning and then we resolve the problem if the planner chooses to introduce the air conditioner.

Based on equation 1, 2 and 7, the social planner's problem is

$$
\max _{c}: N s(T) u(c)
$$

subject to

$$
T=\phi N c+T_{0} ; \text { and } c \leq y \text {. }
$$

The socially optimal consumption $c$ is equal to income $y$ if $y \leq \tilde{c}$; otherwise $c=\widetilde{c}$, where $\tilde{c}$ satisfies $\phi N s^{\prime}\left(\phi N \tilde{c}+T_{0}\right) u(\tilde{c})+s\left(\phi N \tilde{c}+T_{0}\right) u^{\prime}(\tilde{c})=0$. The competitive equilibrium of this model is different from the Pareto optimum shown above. The temperature is an exogenous variable from the individual's perspective. Individual agents spend all of their income on consumption to yield their maximum utility, i.e. $c=y$. In this case, total social welfare $W$ will equal

$$
W=N s\left(\phi N y+T_{0}\right) u(y)
$$

Differentiating the social welfare function with respect to income yields the expression;

$$
\frac{d W}{d y}=\underbrace{\phi N^{2} s^{\prime}\left(\phi N y+T_{0}\right) u(y)}_{\text {Climate Change Effect }}+\underbrace{N s\left(\phi N y+T_{0}\right) u^{\prime}(y)}_{\text {Income Effect }} .
$$

This equation demonstrates that income growth causes two effects. First, income growth causes higher temperature which reduces the survival rate. Second, higher income raises each individual's consumption. The net effect of higher income depends on the tradeoff between the climate change

effect and the direct income effect. If we have a $\widetilde{c}, \frac{d W(\widetilde{c})}{d y}=0$. In this economy, each person maximizes his utility. Social welfare increases with income if $y \leq \tilde{c}$, and decreases with income if $y>\tilde{c}$. Social welfare is not always growing as the aggregate economy grows. Holding technology constant, the environmental feedback effect reduces social welfare.

The planner's problem shifts if the air conditioner is introduced. The air conditioners will be purchased only when equation 4 is satisfied. As proposition 1 shows, higher outdoor temperature and income will increase an individual's willingness to pay. To study the Pareto optimal consumption of the composite commodity and electricity, we focus on the case in which each individual's income is high enough so that each can afford to buy the air conditioner; $\bar{P}>\frac{F}{N}+V$. 
The planner's problem is

$$
\max _{c, q}: N s(q) u(c)
$$

subject to

$$
c+\eta \tau(T-q)+P \leq y, P=\frac{F}{N}+V \text {, and } T=\phi N c+\varphi N \tau(T-q)+T_{0} .
$$

Solving this problem, the consumption for each person will satisfy

$$
\frac{(1+\phi N \eta \tau-\varphi N \tau)}{\eta \tau} s^{\prime}(q) u(c)+s(q) u^{\prime}(c)=0,
$$

where

$$
q=\frac{(1+\phi N \eta \tau-\varphi N \tau) c-(1-\varphi N \tau) y+\eta \tau T_{0}+(1-\varphi N \tau)\left(\frac{F}{N}+V\right)}{\eta \tau} .
$$

In this case, total social welfare $W$ is

$$
W=N s(q) u(c)
$$

Differentiating the total social welfare function with respect to income yields;

$$
\frac{d W}{d y}=N s^{\prime}(q) u(c)\left[\frac{(1+\phi N \eta \tau-\varphi N \tau)}{\eta} \frac{d c}{d y}-\frac{(1-\varphi N \tau)}{\eta \tau}\right]+N s(q) u^{\prime}(c) \frac{d c}{d y} .
$$

Substitute equation 15 into equation 17 ,

$$
\frac{d W}{d y}=-N s^{\prime}(q) u(c) \frac{(1-\varphi N \tau)}{\eta \tau} .
$$

The above equation shows that if $\varphi N \tau>1$, the adaptation innovation actually lowers social welfare as income grows. It implies that the air conditioner efficiency is a key parameter for determining whether social welfare increases by inducing the invention of the air conditioner. If the air conditioners are not "green" enough, the aggregate survival risk imposed by the greater aggregate carbon emissions associated with individual air conditioner adoption lowers social welfare.

Note that the gain in social welfare here depends on the population size. If the population is large enough, the introduction of the air conditioner cannot increase the social welfare since carbon emissions of electricity consumption exacerbates climate change risk.

We now consider the impact of population growth on social welfare holding per-capita income constant. If the population $N$ is large enough, the utility of a single agent is very small. Differentiating total social welfare with respect to the number of people yields:

$$
\frac{d W}{d N}=\underbrace{N s^{\prime}(q) u(c)\left(\phi \tau c-\frac{\varphi \tau c}{\eta}+\frac{\varphi \tau y}{\eta}\right)}_{\text {Climate Change Effect }}-\underbrace{N s^{\prime}(q) u(c)\left(\frac{F}{N^{2}}+\frac{\varphi \tau V}{\eta}\right)}_{\text {Scale Economies in Production }}
$$

This equation highlights two points. First, an increase in the population generates more carbon 
emissions and the resulting climate change reduces the social welfare. Second, the greater demand for air conditioners induces new adaptation innovation. Since there are more people who share the fixed cost of innovation, this increases social welfare. The total effect of population growth depends on this trade-off between these two effects. We define

$$
\widetilde{N}=\sqrt{\frac{F \eta}{\phi \tau c \eta+\varphi \tau y-\varphi \tau c-\varphi \tau V}} .
$$

If $N<\tilde{N}$, social welfare increases with population size. Equation 18 shows that $\widetilde{N}$ increases with the fixed cost of air conditioners $F$ and decreases with the efficiency of air conditioners $\tau$. A higher fixed cost for air conditioners production enhances the scale economy effect. Greater demand for the air conditioning can increase social welfare because it increases the likelihood that this innovation takes place. If the air conditioners are more energy efficient, then the environment can be protected even for a larger total population.

Our pareto planner is solving a one period problem. If there are multiple generations and each generation lives for one period, then the planner will face a dynamic tradeoff if greenhouse gas emissions are a stock pollutant. In this case, the planner would recognize that higher consumption by an early generation will permanently raise the baseline temperature for every subsequent generation and this would increase the death risk for every subsequent generation. To simplify our discussion, we focus on the one period problem.

\section{B The Evolution of Adaptive Technology Efficiency}

In this section, we introduce a producer who can invest more on $\mathrm{R} \& \mathrm{D}$ to develop a more energy efficient technology. In our model, the fixed cost of production $F$ is a function of the efficiency parameter $\tau$, such that

$$
F=F(\tau)
$$

specifically,

$$
F^{\prime}<0 \text { and } F^{\prime \prime}>0
$$

It implies that the $\mathrm{R} \& \mathrm{D}$ investment can improve the efficiency of air conditioner, i.e. less electricity spending on cooling. It implies that energy efficient air conditioner could lead to lower emissions in the economy with more people. The R\&D investment features diminishing returns. Given this set-up, this section discusses the optimal technology selection.

Substitute equation 19 into equation 6 and resolve the optimal problem as shown in equation 14. We can solve for the optimal technology selection that satisfies

$$
F=\tau F^{\prime}+N(y-c-V)
$$

Note that the optimal consumption $c$ satisfies equation 15. Based on this first order condition, we 
derive the relationship between technology selection as a function of key parameters.

We find that the more efficient technology is selected when the population is larger, income is higher or the electricity price is higher. $\frac{\partial \tau}{\partial N}<0, \frac{\partial \tau}{\partial y}<0$, and $\frac{\partial \tau}{\partial \eta}<0$. The technology selected by the producer depends upon the market demand. A larger population reduces the average $\mathrm{R} \& \mathrm{D}$ cost for designing more efficient air conditioners. As individual income increases, people can afford the more efficient technology. If the electricity price is more expensive, people are willing to purchase a more efficient air conditioners.

Recall proposition 2. It shows that the adaption innovation can improve the social welfare if it is energy efficient enough. The efficiency of air conditioners improves if the population increases, income grows or the price of electricity is high. Our findings regarding the relationship between carbon emissions and income (holding other factors constant) resembles the Environmental Kuznets Curve (EKC)(Stokey 1998; Andreoni and Levinson 2001). Climate change adaptive technology is introduced when income is high enough as shown in proposition 1 . The efficiency of air conditioners can be improved as shown in proposition 5.

The "rebound effects" literature has emphasized that increases in energy efficiency can actually increase resource consumption if demand is sufficiently price elastic (Davis 2008). In our setting, consumers will be aware that improvements in air conditioner energy efficiency reduces the price of achieving extra cooling and thus a lower death risk. As equation 16 shows, the optimal indoor temperature decreases with the air conditioner's energy efficiency. $\frac{\partial q}{\partial \tau}<0$ and $\frac{\partial^{2} q}{\partial \tau^{2}}>0$. This discussion highlights that the existence of an EKC for electricity consumption will hinge on the shape of the utility function with respect to consumption and the shape of the death risk function with respect to temperature. If the marginal utility of consumption is high and if the marginal reduction in death risk for a reduction in temperature is low, the agents in this economy will be more likely to reduce their electricity consumption as energy efficiency improves.

In our model, consumers must pay more for the more energy efficient air conditioner because the more efficient technology features a higher fixed innovation cost. This means that people will have less disposable income to purchase extra cooling (an income effect). However, the marginal increase in the fixed cost for the more efficient air conditioner for each individual consumer will be small if the population is large. The income effect will be smaller and the rebound effect will be larger in an economy with a large population. 